\title{
Mostra fotográfica multimídia: espaços de aprendizagem inovadora em educação ambiental
}

\section{Multimedia photographic exhibition: spaces of innovative learning in environmental education}

\author{
Clarissa Felkl Prevedello1; Daniel Vieira Essinger²; Débora Cristina Secchi
}

\section{RESUMO}

Este artigo se refere ao projeto de extensão Mostra Fotográfica Multimídia "Visitando a Cooperativa FRAGETCOOTAFRA", idealizado pelo Núcleo de Gestão Ambiental Integrada da Reitoria do Instituto Federal Sul-riograndense. A proposta teve como objetivo de promover situações de aprendizagem inovadoras sobre a importância socioambiental das cooperativas de reciclagem. A Mostra foi composta por imagens que retratam o dia a dia da Cooperativa, os processos por onde passa cada tipo de resíduo e as pessoas que lá trabalham e que tiram seu sustento da reciclagem. Registros de som do ambiente interno da Cooperativa também fizeram parte da Mostra, propondo maior ambientação dos visitantes ao tema das fotografias, juntamente com imagens registradas pelos próprios cooperativados, revelando seus pontos de vista sobre o trabalho que realizam.

Palavras-chave: Mostra Fotográfica, Extensão, Educação Ambiental, Aprendizagem Inovadora.

\begin{abstract}
This article refers to the extension project entitled Multimedia Photographic Exhibition "Visiting the Cooperative FRAGET-COOTAFRA", conceived by the Federal Institute of Rio Grande do Sul's central administration's Group of Integrated Environmental Management. The proposal was to create situations of innovative learning about the environmental importance of recycling cooperatives. The exhibit consisted of images that portray the daily life of the Cooperative, the processes which each type of waste goes through and the people who work there and who make their living from recycling. Sound records of the Cooperative's work environment were also part of the exhibition, proposing greater ambiance of visitors to the theme of the photographs along with pictures taken by the Cooperative's members themselves, revealing their own points of view on the work they do.
\end{abstract}

Keywords: Photographic Exhibition, Extension, Environmental Education, Innovative Learning.

\footnotetext{
${ }^{1}$ UFRGS - Universidade Federal do Rio Grande do Sul, Porto Alegre/RS - Brasil

${ }^{2,3}$ IFSul - Instituto Federal de Educação, Ciência e Tecnologia Sul-rio-grandense, Pelotas/RS - Brasil.
} 


\section{INTRODUÇÃO}

O trabalho do catador de materiais recicláveis, muitas vezes não é reconhecido, um dos motivos, pode ser a falta de conhecimento sobre o processo da reciclagem. Motivado pela ideia de ampliar a visibilidade dos trabalhadores do FRAGET-COOTAFRA este artigo objetiva apresentar o projeto de extensão Mostra Fotográfica Multimídia "Visitando a Cooperativa FRAGET-COOTAFRA". A concepção para esse projeto surgiu em meio às atividades desenvolvidas pelo Núcleo de Gestão Ambiental Integrada da Reitoria (NUGAI) do Instituto Federal de Educação, Ciência e Tecnologia Sul-riograndense (IFSul), em Pelotas, Rio Grande do Sul, Brasil. O NUGAI tem como uma de suas principais atividades coordenar a coleta seletiva na Reitoria, destinando os resíduos gerados para a FRAGETCOOTAFRA (Cooperativa de Trabalho dos Agentes Ambientais da Associação das Vilas Reunidas Farroupilha, Real, Aurora, Guabiroba, Elza e Treptow).

A Cooperativa foi habilitada para o recolhimento do material reciclável da Reitoria, por meio de seleção realizada por edital. O grupo de agentes ambientais FRAGET-COOTAFRA iniciou sua atuação no ano de 1999 e é composto por cerca de vinte pessoas, que desenvolvem atividade econômica autogerida no setor da triagem de resíduos sólidos (SECCHI; MEDEIROS, 2014). O coletivo é formado, de modo geral, por trabalhadores excluídos do mercado formal de trabalho, que buscam, por meio da organização associativa, uma alternativa de geração de renda, organizados de forma igualitária, sem distinção hierárquica (OBADOWSKI, 2014, SECCHI; MEDEIROS, 2014).

Durante as visitas feitas à Cooperativa, para construção do projeto, os cooperativados relataram que o próprio bairro onde estão localizados desconhecia o trabalho realizado no galpão de reciclagem, que os moradores daquela localidade não costumavam fazer a coleta seletiva e que acreditavam que o trabalho com crianças e jovens iria potencializar uma mudança nesse cenário. No IFSul, após uma consulta com os trabalhadores da Reitoria, foi constatado desconhecimento sobre o destino dos resíduos sólidos descartados, sobre os cooperativados e sobre o trabalho que desenvolvem.

Nesse contexto, o projeto foi pensado com o objetivo de sensibilizar, por meio de uma mostra fotográfica itinerante, a comunidade da Escola Estadual de Ensino Fundamental Marechal Luiz Alves de Lima e Silva, localizada nos arredores da Cooperativa, e os servidores da Reitoria do IFSul, quanto à importância dos trabalhadores organizados em cooperativas de economia solidária como sujeitos do processo de saneamento básico das cidades e como exemplo de organização de trabalho centrada na valorização do ser humano, transformando ambientes de trabalho em locais de educação ambiental.

A ideia de ampliar a visibilidade dos trabalhadores do FRAGET-COOTAFRA apoiou-se na importância da atividade que desenvolvem e na necessidade de se compreender que o processo de reciclagem não termina com o depósito dos resíduos na lata de lixo, pois se trata de um processo complexo, permeado por aspectos econômicos, políticos, sociais e ambientais.

Considerando o que relata Fuão (2015) e IPEA (2012), percebeu-se que, embora o catador tenha um papel tão importante no gerenciamento de resíduos sólidos, ele é marginalizado, e que, portanto, é de grande urgência que a sociedade crie espaços de educação que deem visibilidade ao trabalho realizado nas cooperativas de reciclagem.

A opção por uma mostra fotográfica multimídia, unindo imagem e som, como forma inovadora de educação ambiental, justifica-se, a exemplo de outras iniciativas, como no caso do Museu da Imagem 
e do Som, localizado em São Paulo, Brasil, onde se utiliza a tecnologia aliada à sensibilidade humana na criação artística. Dessa maneira, a exposição oportunizou o desenvolvimento de um espaço de diálogo vivo, que transita entre o registro fotográfico, estático, e o som, dinâmico, conferindo uma atmosfera única para o ambiente de trabalho, transformando-o em ambiente de aprendizagem e transportando o espectador para a realidade a ser representada.

\section{AS COOPERATIVAS DE CATADORES DE MATERIAIS RECICLÁVEIS NO BRASIL}

\subsection{Histórico normativo}

A partir da Lei n. 9.795 (BRASIL, 1999), que instituiu a Política Nacional de Educação Ambiental, as instituições de ensino ficaram incumbidas de promover a educação ambiental de maneira integrada aos programas educacionais que desenvolvem, e a sociedade como um todo, de "manter atenção permanente à formação de valores, atitudes e habilidades que propiciem a atuação individual e coletiva voltada para a prevenção, a identificação e a solução de problemas ambientais" (art. 30, VI).

Nesse contexto, a Política Nacional de Resíduos Sólidos, instituída pela Lei n.12.305 (2010), estabelece como um de seus instrumentos, além da educação ambiental, a coleta seletiva. Terão acesso prioritário aos recursos da União os Municípios que "implantarem a coleta seletiva com a participação de cooperativas ou outras formas de associação de catadores de materiais reutilizáveis e recicláveis formadas por pessoas físicas de baixa renda", conforme art. 18, II, dessa Lei.

Antes mesmo da Política Nacional de Resíduos Sólidos, o Decreto n. 5.940 (2006), havia estabelecido "a separação dos resíduos recicláveis descartados pelos órgãos e entidades da administração pública federal direta e indireta, na fonte geradora, e a sua destinação às associações e cooperativas dos catadores de materiais recicláveis". O art. $5^{\circ}$ do Decreto determina que deverão ser instituídas Comissões para a Coleta Seletiva Solidária, no âmbito de cada órgão e entidade da administração pública federal direta e indireta. Em atendimento a essa obrigação legal, foi implantada a Coleta Seletiva Solidária na Reitoria do IFSul, por meio do NUGAI-Reitoria.

\subsection{Organização de catadores de materiais recicláveis em cooperativas}

O Brasil é o quinto país mais populoso do mundo, com mais de 202 milhões de habitantes, conforme a última estimativa do Instituto Brasileiro de Geografia e Estatística (DIÁRIO OFICIAL DA UNIÃO, 2014), sendo que somente da década de 1970 até os dias atuais o número de pessoas dobrou.

Esse contexto, somado à diminuição da população rural e a consequente migração para as cidades, traz um crescente agravamento da crise ambiental, pois se elevam a utilização insustentável dos recursos hídricos, a ocupação e a destruição de importantes ecossistemas, além das questões sociais, como aumento da violência, da injustiça social, da má distribuição de renda etc. Nesse sentido, o descarte inapropriado de enormes volumes de resíduos tem-se tornado um dos mais graves problemas ambientais contemporâneos.

Os locais de armazenamento e de disposição final tornam-se ambientes propícios para a proliferação de vetores e de outros agentes transmissores de doenças. Pode haver, também, a emissão de partículas e outros poluentes atmosféricos, diretamente pela queima de lixo ao ar livre ou pela incineração de dejetos sem o uso de equipamentos de controle adequados. De modo geral, os impactos dessa degradação estendem-se 
para além das áreas de disposição final dos resíduos, afetando toda a população. (GOUVEIA, 2012, p.1506)

Segundo dados da última Pesquisa Nacional de Saneamento Básico, em 2008, 99,96\% dos municípios brasileiros tinham serviços de manejo de Resíduos Sólidos, porém, 50,75\% deles dispunham seus resíduos em lixões (INSTITUTO BRASILEIRO DE GEOGRAFIA E ESTATÍTISCA, 2008). Embora, segundo a Constituição Federal, o município é o titular dos serviços de limpeza urbana, desde a coleta até sua destinação final, à época da aprovação da Política Nacional de Resíduos Sólidos, a maioria das Prefeituras Municipais ainda não dispunham de recursos técnicos e financeiros para solucionar os problemas ligados à gestão de resíduos sólidos (MINISTÉRIO DO MEIO AMBIENTE, n.d.).

Iniciativas para a redução da quantidade de material descartado em aterros, como a coleta seletiva para posterior reciclagem, ainda caminham lentamente. Conforme Gouveia (2012), "em 1989 identificou-se a existência de 58 municípios com programas de coleta seletiva de lixo no Brasil. Esse número cresceu para 451 municípios em 2000, e para 994 em 2008, em um universo de 5.564 municípios" (GOUVEIA, 2012, p.1506).

Nesse cenário, o desemprego e a precarização do trabalho ao longo das últimas décadas propiciaram que um grande número de trabalhadores enxergasse a catação como forma de subsistência, unido a isso, "a abundância de resíduos sólidos, como latas, garrafas PET, sacos plásticos, papéis e papelões, criou uma nova categoria de trabalhadores: a dos catadores ${ }^{3 \prime \prime}$ (FUÃO, 2015, p.75). Atualmente, segundo dados do Movimento Nacional dos Catadores de Materiais Recicláveis, existem cerca de 800 mil catadores de materiais recicláveis no Brasil. Segundo o Instituto de Pesquisa Econômica Aplicada [IPEA] (2012), esses trabalhadores constituem a base da cadeia produtiva da reciclagem, pois se estima que $90 \%$ de todo o material reciclado no Brasil seja recuperado dos resíduos pelas mãos desses agentes.

Revisão bibliográfica feita pelo IPEA (2012), por ocasião do processo de discussão e de elaboração do Plano Nacional de Resíduos Sólidos, revela que essa parcela de trabalhadores, embora tenha indiscutível importância no processo de reciclagem, vive em condições de exclusão social. A opção pela atividade de catação de recicláveis é quase sempre decorrente da ausência de alternativas, e os vínculos de trabalho são extremamente frágeis. Segundo Fuão (2015, p. 77), pode-se observar, a partir de 2003, uma "explosão" do lixo, que encontrou nas pessoas desempregadas aliados para aumentar a capacidade de absorção da industria da reciclagem, lançando milhares de pessoas à "cata de tudo que é encontrado". "São homens, mulheres e crianças no limite da miserabilidade. Basta ir a um lixão para ver. E são elas que ficam com as crianças quando os parceiros vão embora" (Fuão, 2015, p. 76). A maior parte da população de catadores é representada por mulheres, com escolaridade baixa ( $5^{a}$ a $8^{a}$ série do ensino fundamental em média), cuja renda estima-se não ultrapassar o valor do salário mínimo. Segundo Fuão (2015), por serem de maioria do sexo feminino, as mulheres têm um papel muito importante no trabalho de catação. "São elas que ficam com as crianças quando os parceiros vão embora, e, tendo que alimentá-los, lançam mão daquilo que está mais próximo. O lixão constituía-se em fonte de alimento (orgânico degradado) e lixo seco comercializável (FUÃO, 2015, p. 76).

\footnotetext{
${ }^{3}$ Catadores de materiais recicláveis: coletam os resíduos e os vendem às cooperativas, às associações de triagem, que acondicionam e enviam o material para as fábricas (OBADOWSKI, 2014, p. 9).
} 
Esse quadro de exclusão aponta para a necessidade de políticas públicas que deem conta de reverter a situação de precarização dessa atividade bem como de formalização dos catadores como agentes dentro da cadeia produtiva da reciclagem. As ações que se dão no sentido de afirmar a profissão do catador, fruto da luta dos catadores organizados politicamente, têm pautado as políticas públicas para o fomento da organização desses trabalhadores em cooperativas.

As cooperativas, além de oferecerem maior expectativa de renda em relação à catação individual, são espaços onde a relação de trabalho proporciona a restauração da autoestima e do sentido de pertencimento social desses trabalhadores, na medida em que as pessoas vão tomando consciência da importância do seu trabalho. (GRIMBERG, 2005, p. 25)

Nesse sentido, o "papel das cooperativas está em evidência, principalmente na integração dos catadores nas ações de responsabilidade compartilhada, seu potencial e prioritária participação na logística reversa, coleta seletiva e planos de resíduos sólidos" (NETO, 2013, p. 94).

A Política Nacional de Resíduos Sólidos tem sido um importante mecanismo no sentido de organização dos catadores, pois os insere formalmente na cadeia de comercialização de recicláveis. A Política tem como instrumento o incentivo à criação e ao desenvolvimento de cooperativas ao mesmo tempo em que aponta para os municípios a tarefa de implantar a coleta seletiva com a participação desses coletivos.

\section{EDUCAÇÃO AMBIENTAL PARA ALÉM DA RECICLAGEM}

A coleta seletiva é uma metodologia de gestão dos resíduos sólidos que propõe a volta da matéria prima para a produção, diminuindo o desperdício dos materiais que ainda possuem vida útil. Para além da questão técnica de gestão, a segregação dos resíduos deve sempre estar ligada à educação, no sentido de promover a reflexão sobre o hábito de consumir. Nesse sentido, segundo Calderoni (1996, apud FELIX, 2007), a reciclagem, na sua essência, é uma maneira de educar e fortalecer nas pessoas o vínculo afetivo com o meio ambiente, despertando o sentimento do poder de cada um para modificar o meio em que vive.

Loureiro (2002) define Educação Ambiental como um processo educativo e social que tem por finalidade a construção de valores, conceitos, habilidades e atitudes que possibilitem o entendimento da realidade da vida e a atuação consciente e responsável de atores sociais individuais e coletivos no ambiente, tendo em vista a qualidade de vida individual, coletiva e do planeta.

Assumindo-se essa concepção de Educação Ambiental como verdadeira, deve-se pensar em uma proposta extensionista que vá além da mera transmissão de informações técnicas sobre o meio ambiente e os conceitos da Ecologia. Dentro dessa perspectiva de Educação Ambiental, não há lugar para concepções reducionistas de meio ambiente, deve-se pensá-lo sistemicamente, como bem define Reigota (1994).

A educação ambiental, quando trata da coleta seletiva, procura uma prática de reflexão individual, busca transformar o indivíduo - não apenas o meio ambiente - e vê o resíduo dentro de um contexto sistêmico. "O resíduo sólido é uma questão a ser abordada de forma ampla, contemplando os aspectos econômico, político, sociológico, psicológico, sanitário, 
afetivo, mitológico e ambiental". (GONÇALVES, 2003 como citado GUANABARA; GAMA; EIGENHEER, 2008, p. 122).

\subsection{A fotografia e o som: inovação em educação ambiental}

A utilização das Tecnologias da Informação e Comunicação (TICs) na aprendizagem já é uma realidade no contexto educacional, muito discutida e aplicada em diferentes contextos e dimensões, assim, sua adoção não pode mais ser tratada como novidade. Desse modo, a educação passa por um momento em que o conceito de inovação centrado apenas no desenvolvimento tecnológico é menos sustentável, pois é mais suscetível de ser rapidamente superado, por isso, depende de novas escolhas (BROWN, 2010). De acordo com Motta e Scott (2014), deve-se pensar em uma relação cíclica dos três conceitos que envolvem inovação na aprendizagem: ciência, tecnologia e inovação, ao contrário da visão tradicional linear e unidirecional.

Nesse contexto, a inovação pedagógica se distancia da noção de novidade tecnológica e centra-se na intencionalidade da mudança e da criação de situações de aprendizagem diferenciadas e que podem influenciar diretamente a ciência, estabelecendo-se no início do processo de produção do conhecimento (QUADROS; MARQUES, 2013; MOTTA ; SCOTT, 2014). "O foco da inovação está na sua ação de mudança intencional, bem planejada, deliberada, criativa, crítica e conscientemente assumida na criação de situações de aprendizagem diferenciadas e novas para melhorar a prática educativa" (QUADROS; MARQUES, 2013, p. 8).

Dessa maneira, a Mostra Fotográfica Multimídia, utilizando-se da imagem e do som, propôs uma situação de aprendizagem inovadora, transformando o local de trabalho em um local de aprendizagem.

A imagem foi eleita como principal mecanismo para a Mostra, devido à familiaridade com a linguagem e seu poder de influência. "Diariamente somos cercados por imagens, que vêm tanto da arte, quanto de fontes comerciais e do entretenimento. Elas contêm mensagens que podem influenciar mais do que aquelas contidas em textos verbais" (BALESTRERI, 2005, p. 116).

O som, por sua vez, tem o potencial de desenvolver uma atmosfera única, capaz de estabelecer conexão com a construção do espaço da exposição. Quando se utiliza o som em exposições, conforme afirma Campesato e Iazzetta (2006, p. 776), "o espaço adquire uma importância vital na maior parte desses trabalhos, atuando não como agente de delimitação da obra, mas como elemento integrante da mesma". Campesato e Iazzetta (2006, p. 776) também destacam que o som é muito utilizado quando os ambientes que abrigam a arte sonora diferem dos espaços tradicionais e neutros, como as salas de concerto de música, e que se aproximam "mais de ambientes com uma conotação mais ligada à plasticidade como galerias de arte, museus ou outros espaços alternativos".

Desse modo, a união da fotografia com o som auxilia no estabelecimento de um espaço que leva em consideração as relações e as interações entre os elementos e o contexto da exposição, aproximandose, dessa maneira, da instalação, pois "o espaço está em diálogo ativo entre as coisas e as pessoas que ele contém" (GOLDBERG, 2001 apud CAMPESATO; IAZZETTA, 2006, p. 776). Entende-se por instalação, segundo Campezzato e Iazzeta (2006), o "gênero da arte que, pelo uso de materiais escultóricos e outras mídias, busca modificar a maneira que um sujeito experiencia um espaço particular, desse modo aproximando-se das artes performáticas". 
Assim, a Mostra proporcionou aos espectadores uma experiência por meio da arte como forma de conhecimento, aproximando-se da Arte Educação de uma maneira interativa e dinâmica.

Vivenciar a qualidade estética é uma experiência que transborda para todas as áreas do ser e do conhecimento. Nesse sentido, a pessoa esteticamente "afinada" por suas referências pessoais e culturais torna-se mais atenta à percepção de si e do meio. Sabe como dar forma às sensações e ideias. Sabe discriminar, escolher, conceber e atuar. (RIZZI; ANJOS, 2010, p. 34)

Um dos objetivos da Arte Educação consiste em "ensinar aos estudantes como apreciar diferentes obras artísticas e desenvolver seu senso crítico no momento de relacionar-se com qualquer tipo de evento artístico ou que faça parte do que atualmente começa a denominar-se como cultura visual" (HERNÁNDEZ, 2000, p.88). Partindo dessa premissa, sua relevância encontra-se no fato de oportunizar aos estudantes reconhecer, compreender e desenvolver senso crítico sobre o caráter das obras de arte.

Dessa forma, a condução do usuário-estudante à imersão na obra-imagem é responsabilidade da Arte Educação, considerada como Agente. Dessa maneira, ao planejar uma exposição com objetivos de aprendizagem, é necessário conhecer as possíveis leituras dos usuários-estudantes, para que se possa compreender suas releituras e considerar suas respostas. Essa leitura é conduzida por um conjunto de perguntas que motivam o estudante a refletir e a responder. A qualidade das respostas define 0 nível do estudante quanto à sua capacidade de abstração e sua competência para perceber, estabelecer relações e, mais tarde, avaliar e sugerir.

Nesse momento, podem-se distinguir os níveis de pensamento estético, de acordo com Rossi (2003). Primeiro, o espectador percebe o sentimento da personagem da obra, quando se detém apenas na percepção dos componentes concretos e formais da composição. O segundo nível mostra um espectador que percebe o sentimento do artista transferido na obra: quando percebe o plano subjetivo da imagem, o espectador passa a ler aspectos implícitos da imagem. No terceiro nível, percebe o sentimento desvinculado da produção: destaca a abstração do tema da obra, quando relaciona a subjetividade do artista com a subjetividade do observador.

Sendo assim, a leitura de imagens propiciada pela Mostra não se trata de uma atitude passiva, pois a imagem convida o espectador a sentir, a pensar, a refletir sobre a obra. Segundo Rossi (2011), a imagem nos leva a fazer perguntas para ela, mesmo quando não nos damos conta de que a estamos interpretando, e, assim, é estabelecida uma espécie de diálogo implícito com a obra, que busca sua compreensão.

Quando o leitor esta apreciando uma imagem, se defronta com um quebra-cabeça ao tentar responder a questão: onde devem ser encontradas sua beleza e qualidade? Em outras palavras: quem ou o quê é o responsável, intencionalmente, pela natureza da obra? (FREEMAN; PARSONS, 1999 apud ROSSI, 2011, p. 36)

Por isso, que as imagens foram empregadas, para estimular os espectadores, pois estabelecem, segundo Rossi (2011), uma relação com o mundo (nelas representado), com o produtor das imagens e com o leitor (pessoa que as vê).

Por esse tipo de relação com a obra artística, a utilização de mostra fotográfica multimídia para transformar um espaço não comumente utilizado para educação se aproxima das estratégias 
pedagógicas inovadoras apresentadas por Motta e Scott (2014), retiradas de Laurillard (2002), tratase de processos de ensino e de aprendizagem que se afastam do nível discursivo, com foco mais teórico, conceitual e descritivo, e se aproximam do nível experimental em que o foco está nas atividades práticas. Embora os dois níveis sejam interativos, no primeiro, o discursivo, a interação se dá de maneira estratificada hierárquica em que o professor tem o controle das relações e do conteúdo, ao contrário, no segundo, o experimental, a interação é adaptativa e descentralizada. (MOTTA; SCOTT, 2014).

Assim, por meio da Mostra, se oportunizou o transporte do espectador para o "mundo real", conforme ponto de vista de Callenbach (2006), pois existem maiores possibilidades de entendimento mútuo e de cooperação se compreendermos que, embora existindo em nosso consciente - de forma abstrata, portanto -, os valores têm consequências físicas no mundo real.

Desse modo, uma exposição multimídia se mostra relevante para o ensino e a divulgação da educação ambiental. Conforme aponta Callenbach (2006), as questões ambientais são, na maioria das vezes, discutidas do ponto de vista "prático", mas o que a maioria dos debates ecológicos envolve, na verdade, são "conflitos de valores". Para o autor:

O movimento ambientalista baseia-se antes em valores estéticos e morais sobre o que é certo, cabível, belo ou satisfatório do que em argumentos econômicos ou científicos e que os conflitos de valores ocorrem tanto no íntimo de uma pessoa quanto entre as pessoas, apesar de nem sempre querermos reconhecê-los. (CALLENBACH (2006 apud RIZZI; ANJOS, 2006, p. 29)

Além disso, estabelece o local de trabalho como um ambiente de educação por excelência, capaz de desenvolver o ser humano em sua totalidade, na perspectiva ontológica, e não resumi-lo a apenas emprego, tarefa, ocupação (FRANCO; FRIGOTTO (1993).

\section{A MOSTRA FOTOGRÁFICA MULTIMÍDIA}

A metodologia do projeto foi elaborada durante reuniões na Escola Estadual de Ensino Fundamental Marechal Luiz Alves de Lima e Silva, no FRAGET-COOTAFRA, conforme Figura 1(A), e na Reitoria do IFSul. Nesses encontros, foi apresentada a proposta inicial e foram ouvidas sugestões, tanto da Escola como da Cooperativa, para definir-se um cronograma de trabalho de forma coletiva.

Nas semanas seguintes, os membros da equipe extensionista realizaram visitas à Cooperativa para o registro do trabalho dos cooperados, por meio de captação de imagens e de som, sob uma perspectiva de revelar a relação de trabalho solidária entre os cooperativados e a dinâmica do processo de separação dos resíduos. Durante essas incursões, todos os ambientes da Cooperativa foram percorridos, entre eles: setor administrativo, mesa de triagem, fragmentadora, prensa, recebimento e despacho de material. Nessa fase, os cooperados foram convidados a contribuir com fotos, registrando seu ponto de vista sobre o trabalho.

O próximo passo foi a escolha das imagens para a exposição e para o catálogo fotográfico-pedagógico, feita conjuntamente pelos membros do projeto e pelos cooperativados. Após, foi realizada a edição das fotografias selecionadas. A seguir, iniciou-se a fase de desenvolvimento da exposição, que compreendeu a definição dos espaços físicos onde seria feita a Mostra, a impressão de fotografias, a edição de som e a elaboração dos textos que comporiam a Mostra e o catálogo. 
A Mostra foi composta por um texto de apresentação, 24 fotografias em tamanho $60 \mathrm{~cm} \times 42 \mathrm{~cm}$, expostas em cavaletes de madeira ou fixadas em paredes, de acordo com o local. Durante o passeio pela exposição, o espectador pôde fazer o uso de fone multimídia, ambientando-se com os sons captados na Cooperativa. As fotos foram dispostas para que o visitante da Mostra entendesse seu papel no ciclo de vida dos bens de consumo, bem como a importância das cooperativas de reciclagem nesse processo. As fotos registradas pelos cooperados, por sua vez, foram disponibilizadas em monóculos.

A Mostra foi inaugurada na Escola Estadual de Ensino Fundamental Marechal Luiz Alves de Lima e Silva, Figura $1(B)$, onde foi associada à oficina sobre fotografia e sobre resíduos sólidos e à visita guiada à FRAGET-COOTAFRA, Figura 1 (C, D). A execução dessa atividade ocorreu em quatro momentos. No primeiro, foi realizada uma fala introdutória e contextualizada sobre fotografia, abordando temas como técnica de captar imagens através da luz e zoom das lentes das câmeras fotográficas. No segundo momento, aconteceu uma explicação sobre a problemática do lixo e a importância da reciclagem. No terceiro, realizou-se uma prática fotográfica com os estudantes, que foram divididos em grupos e fotografaram, dentro da temática do lixo/reciclagem, o percurso desde a escola até a Cooperativa, utilizando celulares com câmeras. Após chegarem à Cooperativa, aconteceu uma visita guiada pelo galpão. No momento final, os estudantes escreveram sobre as impressões que tiveram durante e após a atividade e suas ideias sobre a problemática do lixo/reciclagem. As fotos tiradas pelos estudantes foram editadas e fizeram parte de um vídeo que integrou a Mostra Fotográfica durante sua passagem pela Escola.

Na sequência, a exposição percorreu, durante um mês, os ambientes de trabalho da Reitoria, Figura $1(E, F, G)$. O encerramento da Mostra ocorreu na sede da FRAGET-COOTAFRA, onde esteve aberta para os cooperativados, seus familiares e a comunidade do entorno, Figura $1(\mathrm{H})$.

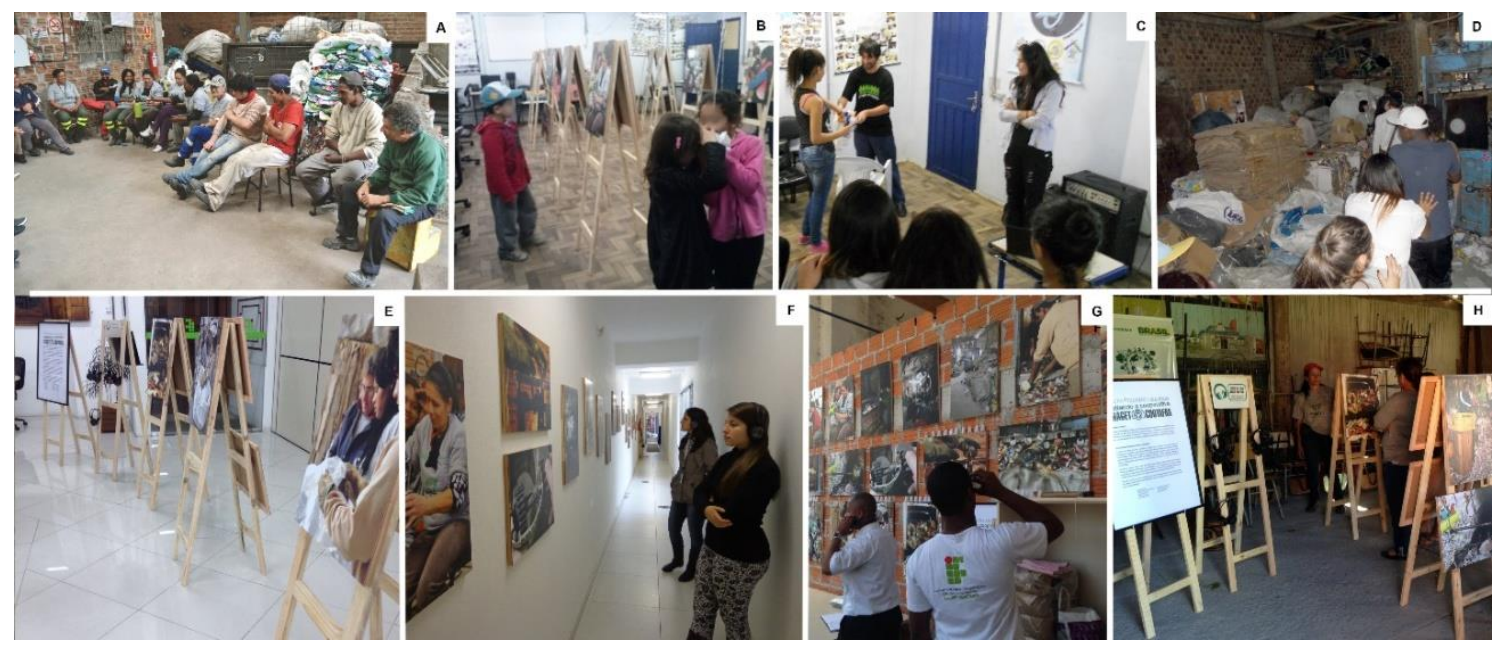

Figura 1. (A) Reunião na Cooperativa; (B) Mostra na Escola; (C) Oficina sobre fotografia e reciclagem na Escola; (D) Visita da Escola na FRAGET-COOTAFRA; (E), (F) e (G) Mostra nos ambientes da Reitoria e (H) Encerramento da Mostra na FRAGET-COOTAFRA.

Fonte. Elaboradas pelos autores.

Ao final, foi elaborado, com base nas atividades realizadas e nos dados coletados durante o projeto, o catálogo fotográfico-pedagógico da Mostra (Figura 2), abordando assuntos como meio ambiente, reciclagem, economia solidária e utilização de mídias, especificamente fotografia e som, como ferramentas na educação. O catálogo traz, ainda, uma apresentação da Cooperativa, abordando sua história, desafios enfrentados e perspectivas futuras. Essa obra foi distribuída para instituições de 
ensino como forma de socialização da proposta pedagógica desenvolvida na Escola e no IFSul durante o projeto.

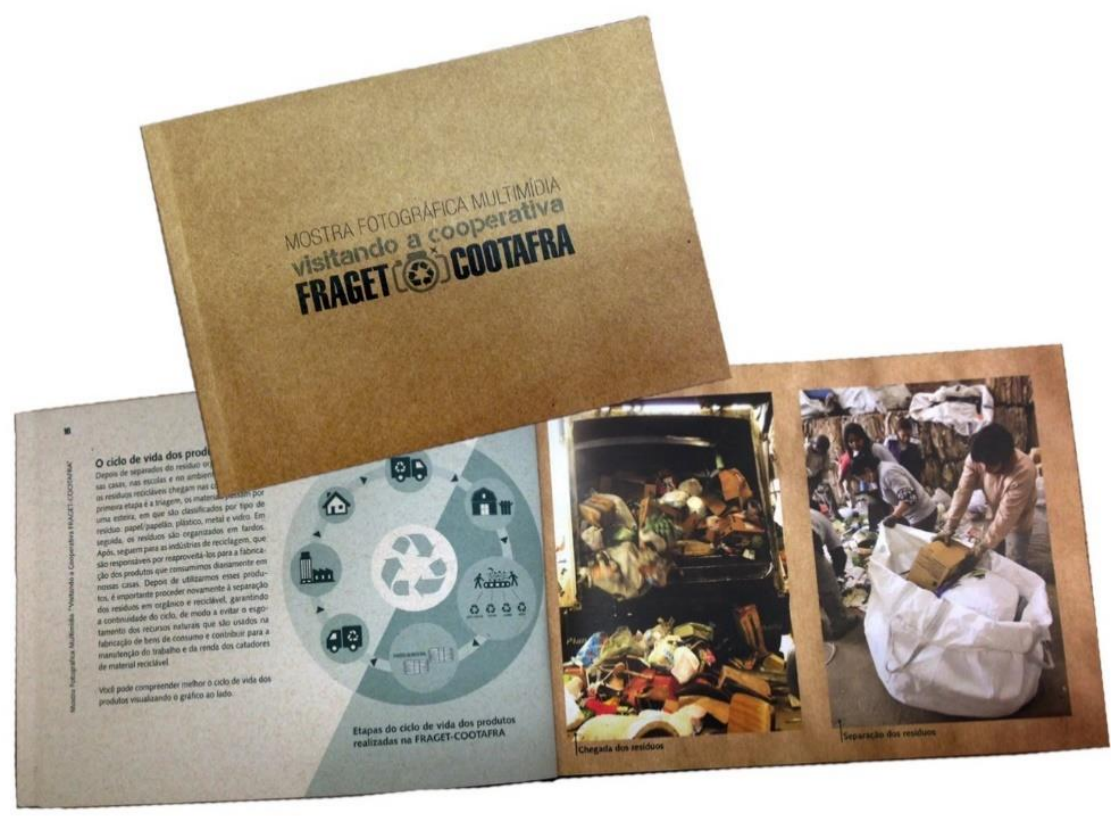

Figura 2. Catálogo fotográfico-pedagógico da Mostra

\section{CONCLUSÃO}

Conclui-se que o projeto contribuiu para uma maior conscientização, tanto da comunidade do IFSul quanto da Escola, sobre a importância dos trabalhadores organizados em cooperativas de economia solidária como sujeitos do processo de gestão dos resíduos sólidos e como exemplo de organização de trabalho centrada na valorização do ser humano. Além disso, a proposta desenvolvida por este trabalho tem potencialidades para ser utilizada como estratégia pedagógica inovadora em Educação Ambiental. A utilização das TICs nesse contexto proporcionou para as comunidades da Escola do IFSul um espaço de reflexão sobre as questões centrais do projeto.

Ao final da atividade de extensão, mais de 500 pessoas haviam visitado a Mostra, que integrou a educação com o trabalho, demonstrando que a aprendizagem não precisa estar limitada somente ao ambiente escolar, mas que deve fazer parte da vida do indivíduo diariamente e, por isso, estar presente, também, no ambiente de trabalho.

O projeto propiciou a ampliação da visibilidade dos trabalhadores do FRAGET-COOTAFRA, valorizando e reconhecendo o trabalho desenvolvido pelos cooperativados como uma atividade especializada, que requer conhecimentos específicos para seu exercício, ao mesmo tempo em que atuou no sentido de desmitificar o trabalho do catador como sendo desorganizado e informal.

Além disso, o projeto auxiliou a consolidação das ações de educação ambiental do NUGAI; por meio dessa ação, os servidores puderam conhecer o trabalho e a forma de organização das pessoas que obtêm renda por meio da reciclagem, o que serviu de estímulo para os colegas da Reitoria aderirem à coleta seletiva solidária.

Durante a fase de planejamento do projeto na Escola, os professores haviam apontado para a dificuldade de lidar com a presença de celulares dentro da sala de aula, porém, segundo relato da coordenadora pedagógica, após a oficina sobre fotografia e resíduos sólidos, alguns docentes 
passaram a utilizar a fotografia, por meio de telefones celulares, como recurso didático, devido à repercussão que a atividade pedagógica teve entre os estudantes. Desse modo, considerou-se esse resultado muito importante, uma vez que a relação entre a tecnologia e o ensino ainda é, muitas vezes, conflitante e deve ser objeto de discussão nas escolas. Conclui-se que o projeto de extensão contribuiu para a reflexão sobre a utilização desse tipo de recurso nos processos de aprendizagem.

Por fim, a aproximação da Escola e do IFSul, por meio do projeto, sinalizou para a realização de trabalhos futuros, assim como houve a verificação da necessidade de ampliar esse tipo de ação na comunidade do entorno da Cooperativa.

\section{CONSIDERAÇÕES FINAIS}

Inicialmente falar de formação docente é sempre polêmico e emergente, além disso, não há senso comum ao pensar em como deveriam ser os momentos de formação docente. A essa temática associa-se a valorização social do profissional professor e isso está bastante desgastado hoje em dia, por inúmeros motivos, sendo também exigido desde familiares até políticas já legisladas. Neste sentido, o delineamento do artigo é se propõe a fazer pensar sobre alguns momentos de formação docente que ocorreram no curso de extensão e que muito podem contribuir para o seu fazer docente e compartilhados com os demais colegas professores.

Assim, aponta-se que é uniforme e unânime que os professores necessitam de formação docente, sob vários aspectos sejam eles específicos para sua sala de aula como área de conhecimento, como para atender as novidades das gerações de hoje. Essa formação também poderia abranger áreas não contempladas em suas graduações, como por exemplo, a lei do bullying, questões de gênero, multiculturas, e outros.

\section{AGRADECIMENTOS}

Núcleo de Economia Solidária do Campus Pelotas (NESOL) e Universidade Federal de Pelotas/Rádio Federal FM 107.9. Fonte de fomento e apoio: IFSul/PROEX - Edital No 03/2014.

\section{REFERÊNCIAS}

BALESTRERI, Laudete Vani. Metodologia do Ensino das Artes Visuais. Santa Maria: UFSM. Disponível em: http://coral.ufsm.br/lav/noticias1arquivos/apostilalav. pdf. Acesso em 20 set. 2014.

BRASIL. Decreto Federal no 5.940, de 25 de outubro de 2006. Institui a separação dos resíduos recicláveis descartados pelos órgãos e entidades da administração pública federal direta e indireta, na fonte geradora, e a sua destinação às associações e cooperativas dos catadores de materiais recicláveis, e dá outras providências. Diário Oficial [da] República Federativa do Brasil, Brasília, DF, 26 out. 2006.

BRASIL. Lei no 12.305, de 2 de agosto de 2010. Institui a Política Nacional de Resíduos Sólidos; altera a Lei no 9.605, de 12 de fevereiro de 1998; e dá outras providências. Diário Oficial [da] República Federativa do Brasil, Brasília, DF, 3 ago. 2010. 
BRASIL. Lei no 9.795, de 27 de abril de 1999. Dispõe sobre a educação ambiental, institui a Política Nacional de Educação Ambiental e dá outras providências. Diário Oficial [da] República Federativa do Brasil, Brasília, DF, 28 abr. 1999.

BROWN, Tim. Design Thinking: uma metodologia poderosa para decretar o fim das velhas ideias. Rio de Janeiro: Campus, 2010.

CALLENBACH, Ernest. Valores. In: STINE, Michael R.; BARLOW, Zenobia (Org.) Alfabetização ecológica: a educação das crianças para um mundo sustentável. São Paulo: Cultrix, 2006.

CAMPESATO, Lílian; IAZZETTA, Fernando. Som, espaço e tempo na arte sonora. In: XVI Congresso da Associação Nacional de Pesquisa e Pós-graduação em Música (ANPPOM). Brasília: 2006, p. 775-780. Disponível em: <http://www.eca.usp.br/prof/ iazzetta/papers/anppom_2006.pdf> Acesso em: mar. 2014.

Diário Oficial da União. n. 252, 30 dezembro 2014. Seção I, p.110. Brasília, DF, 2014.

FELIX, Rozeli Aparecida Zanon. Coleta seletiva em ambiente escolar. Revista Eletrônica do Mestrado em Educação Ambiental, Rio Grande, v.18, jan./ jun. 2007. Disponível em <http://www.remea.furg.br/>. Acesso em: 28 abr. 2010.

FRANCO, Maria A. Ciavatta; FRIGOTTO, Gaudêncio. As faces históricas do trabalho: como se constróem as categorias. R. Bras. Est. Pedag., Brasília, v.74, n.178, p.529-554, set./dez. 1993. Disponível em: <http://rbep.inep.gov.br/index.php/RBEP/article/ viewFile/308/309>. Acesso em: 16 jun. 2015.

FUÃO, Fernando Freitas. Lixivia (i)mundi. Porto Alegre: UFRGS, 2015.

GOUVEIA, Nelson. Resíduos sólidos urbanos: impactos socioambientais e perspectiva de manejo sustentável com inclusão social. Ciênc. saúde coletiva, Rio de Janeiro , v. 17, n. 6, p. 1503-1510, June 2012 . Disponível em: <http://www.scielo.br/scielo.php? script=sci_arttext\&pid=S1413-81232012000600014\&lng=en\&nrm=iso>. Acesso em 12 mar. 2014.

GRIMBERG, Elisabeth. Coleta seletiva com inclusão social: Fórum Lixo e Cidadania na Cidade de São Paulo. Experiência e desafios. São Paulo: Instituto Pólis, 2007. (Publicações Pólis, 49)

GUANABARA, Rachel; GAMA, Thais; EIGENHEER Emílio Maciel. Os resíduos sólidos como tema gerador: da Pedagogia dos Três R's ao risco ambiental. Revista Eletrônica do Mestrado em Educação Ambiental, Rio Grande, v. 21, jul./ dez. 2008. Disponível em <http://www.remea.furg.br/>. Acesso em: 28 abr. 2010.

HERNÁNDEZ, Fernando. Cultura visual, mudança educativa e projeto de trabalho. Porto Alegre: Artes Médicas, 2000.

INSTITUTO BRASILEIRO DE GEOGRAFIA E ESTATÍTISCA, Pesquisa Nacional de Saneamento Básico, 2008, E-book. Disponível em < http://www.ibge.gov.br/home/estatistica/ populacao/condicaodevida/pnsb2008/PNSB_2008.pdf > . Acesso em: 14 março de 2014.

INSTITUTO DE PESQUISA ECONÔMICA APLICADA. Diagnóstico sobre Catadores de Resíduos Sólidos, 2012. E-book. Disponível em < http://www.silvaporto.com.br/admin/down loads/CATADORES_BRASIL_IPEA_2012.pdf > . Acesso em: 12 março de 2012.

LOUREIRO, Carlos Frederico Bernardo. Educação ambiental e movimentos sociais na construção da Cidadania ecológica e planetária. In: LOUREIRO, Carlos Frederico Bernardo; 
LAYRARGUES, Philippe Pomier. \& CASTRO, Ronaldo Souza. de. (Orgs.) Educação Ambiental: repensando o espaço da cidadania. 2a edição. São Paulo: Cortez, 2002.

Ministério do Meio Ambiente. (n.d.). A Problemática "Resíduos Sólidos". Recuperado em 28 fevereiro, 2015 de http://www.mma.gov.br/cidades-sustentaveis/residuos-solidos/poli tica-nacionalde-residuos-solidos/contextos-e-principais-aspectos>.

MOTTA, Ronaldo; SCOTT, David. Educando para a Inovação e aprendizagem independente. Rio de Janeiro: Elsevir, 2014.

NETO, Tiago. A Política Nacional de Resíduos Sólidos: Os Reflexos nas Cooperativas de Catadores e a Logística Reversa. Revista Diálogo, Canoas, n. 18, 2011. Disponível em < http://retosalsur.org/wp-content/uploads/2013/08/A-Politica-Nacional-de-Residuos-Solidos-e-asCooperativas-Neto-2011.pdf>. Acesso em: 12 março de 2012.

OBADOWSKI, Janaina Novicki. As cooperativas de reciclagem e as questões ambientais. In: PREVEDELLO, Clarissa Felkl; ESSINGER, Daniel Vieira; SECCHI, Débora Cristina (Org.). Mostra Fotográfica Multimídia "Visitando a Cooperativa FRAGET-COOTAFRA". Pelotas: IFSul, 2014. p. 8-11.

QUADROS, Amanda Maciel de. MARQUES, Tania Beatriz Iwaszko. Inovação ou Novidade? Práticas Educativas e Tecnologias Digitais de Rede. Renote, 2013. v. 11, n. 2, nov., p. 1-16. Disponível em: Acesso em 20 jul. 2015 de http://goo.gl/NCVesk.

REIGOTA, Marcos. Educação Ambiental. 6 ed. São Paulo: Brasiliense, 1994.

RIZZI, Maria Christina de Souza Lima; ANJOS, Ana Cristina Chagas dos. Arte-educação e meio ambiente: apontamentos conceituais a partir de uma experiência de arte-educação e educação ambiental. ARS (São Paulo) [online]. 2010, vol.8, n.15, p. 26-35. Disponível em: <http://www.scielo.br/pdf/ars/v8n15/a03v8n15.pdf.> Acesso em: mar. 2014.

ROSSI, Maria Helena Wagner. Imagens que falam: leitura da arte na escola. 5 ed. Porto Alegre: Mediação, 2011.

SECCHI, Débora Cristina; MEDEIROS, Paola Almeida. A Cooperativa de Trabalho dos Agentes Ambientais FRAGeT-COOTAFRA. In: PREVEDELLO, Clarissa Felkl; ESSINGER, Daniel Vieira; SECCHI, Débora Cristina (Org.). Mostra Fotográfica Multimídia "Visitando a Cooperativa FRAGETCOOTAFRA". Pelotas: IFSul, 2014. p. 12-14. 